\title{
El inicio temprano de la terapia antirretroviral en adultos asintomáticos con VIH supera al diferido
}

\author{
Early initiation of antiretroviral therapy in asymptomatic adults with HIV overcomes the deferred one
}

Insight Start Study Group. N Engl J Med. 2015;373(9):795-807.

\section{Objetivos}

Evaluar riesgos y beneficios de iniciar terapia antirretroviral (TARV) en pacientes con virus de inmunodeficiencia humana (VIH) asintomáticos con recuento de CD4+ mayor a $500 / \mathrm{mm}^{3}$, en comparación con el inicio diferido (con menos de $350 / \mathrm{mm}^{3}$ ).

\section{Diseño}

Ensayo clínico controlado y aleatorizado.

Lugar

Estudio multicéntrico realizado en 215 centros, en 35 países.

\section{Pacientes}

Se enrolaron 4.685 participantes mayores de 18 años, con diagnóstico de $\mathrm{VIH}$, en buen estado de salud: puntaje de Karnofsky $\geq 80 \%{ }^{1}$, vírgenes de tratamiento, asintomáticos, con recuento CD4+ >500 células $/ \mathrm{mm}^{3}$.

\section{Intervención}

Se aleatorizó en dos grupos: 2.326 a inicio inmediato de TARV y 2.359 a inicio diferido.

\section{Medición de resultados principales}

La metodología de recolección de datos fue la misma para ambos grupos. El seguimiento promedio fue de tres años. El resultado primario compuesto incluyó: muerte por síndrome de inmunodeficiencia adquirida (SIDA), evento marcador de SIDA o evento grave no relacionado al SIDA. El último incluía: infarto agudo de miocardio (IAM), accidente cerebrovascular (ACV), cirugía de revascularización miocárdica (CRM), enfermedad renal terminal (inicio de hemodiálisis o trasplante renal), enfermedad hepática descompensada, cáncer no secundario al SIDA, muerte (atribuida a estas enfermedades o por cualquier causa no secundaria al SIDA). Se realizó análisis por intención de tratar.

\section{Resultados principales}

En base a un análisis interino realizado por una comisión independiente de revisión de datos y seguridad, se determinó que se había demostrado la superioridad del inicio temprano (Tabla 1) y se recomendó que a los pacientes del grupo de TARV diferida se les ofreciera iniciar el tratamiento.

Tabla 1: Resultados primarios y secundarios de la terapia antirretroviral temprana vs. diferida

\begin{tabular}{l|c|c|c|c|c}
\multicolumn{1}{c|}{$\begin{array}{c}\text { Resultado } \\
\text { Primario compuesto }\end{array}$} & $\begin{array}{c}\text { Inicio temprano } \\
\mathbf{N = 2 . 3 2 6}(\%)\end{array}$ & $\begin{array}{c}\text { Inicio diferido } \\
\mathbf{N = 2 . 3 5 9}(\%)\end{array}$ & $\begin{array}{c}\text { RR } \\
\text { (IC 95\%) }\end{array}$ & $\begin{array}{c}\text { NNT a 3 años } \\
\text { (IC 95\%) }\end{array}$ & $\begin{array}{c}\text { p } \\
\text { (\%) }\end{array}$ \\
\hline Evento grave 2dario a SIDA & $42(1,8 \%)$ & $96(4,1 \%)$ & $0,43(0,30 \mathrm{a} 0,62)$ & $44(31 \mathrm{a} 77)$ & $<0,001$ \\
\hline Evento grave no 2dario a & $14(0,6 \%)$ & $50(2,1 \%)$ & $0,28(0,15 \mathrm{a} 0,50)$ & $66(45 \mathrm{a} 111)$ & $<0,001$ \\
\hline SIDA & $29(1,2 \%)$ & $47(2 \%)$ & $0,61(0,38 \mathrm{a} 0,97)$ & $27(67 \mathrm{a} 1000)$ & 0,04 \\
\hline
\end{tabular}

RR: Riesgo Relativo; NNT: Número necesario a tratar para evitar un evento, IC 95\%: Intervalo de confianza del 95\%

\section{Conclusiones}

El inicio de TARV en adultos $\mathrm{VIH}+$ con un recuento de CD4+ mayor a $500 / \mathrm{mm}^{3}$ provee beneficios netos sobre el inicio diferido.
Fuente de financiamiento: Instituto Nacional de Alergias, Enfermedades Infecciosas y otras enfermedades.

\section{Comentario}

En 2005 la Fuerza de Tareas Preventivas de los Estados Unidos (sigla en inglés, USPSTF) recomendaba el rastreo de HIV a personas con elevado riesgo de contraer VIH y a embarazadas. Recientemente actualizó su recomendación de rastreo de HIV, ampliando la recomendación a la población general de 15 a 65 años (fuerte recomendación o tipo A)². Este estudio demostró que el inicio inmediato de TARV disminuye significativamente el riesgo de padecer tanto eventos graves relacionados al SIDA como eventos graves no relacionados al SIDA (con bajos NNT a tres años), aportando mayor validez a la recomendación de rastreo en la población general. Es importante considerar que los individuos que comienzan TARV tienen indicación de continuarlo de por vida, por lo que se necesitaría mejor evidencia acerca de los efectos adversos a largo plazo de la TARV, incluyendo riesgo cardiovascular y daño renal.

\section{Conclusiones del comentador}

Más allá de la robustez de la evidencia a favor del rastreo en población general y el inicio del tratamiento temprano, debemos considerar la importancia de poner en primer plano los valores, las creencias y las preferencias del paciente. Nuestro rol debería enfocarse en brindarle el apoyo y el tiempo necesario para afrontar el diagnóstico de una enfermedad crónica, por el momento incurable. Debemos otorgarle la información y las herramientas que le permitan tomar la decisión de recibir un tratamiento (o no) por el resto de su vida, con drogas de las cuales conocemos los beneficios pero no completamente los riesgos a largo plazo.

Alan Gabriel Gauna [ Servicio de Medicina Familiar y Comunitaria del Hospital Italiano de Buenos Aires, alan.gauna@hospitalitaliano.org.ar]

Gauna AG. El inicio temprano de la terapia antirretroviral en adultos asintomáticos con VIH supera al diferido. Evid Act Pract Ambul. 2016 ;19(3)83. Comentado de: INSIGHT START Study Group, Lundgren JD, y col. Initiation of Antiretroviral Therapy in Early Asymptomatic HIV Infection. NEJM. 2015;373(9):795-807. PMID: 26192873.

Referencias:

1. Kamofsky DA, y col. "The use of nitrogen mustards in the palliative treatment of carcinom." CANCER 1948;1:634-56

2. Moyer VA, on behalf of the U.S. Preventive Senvices Task Force. Screening for HIV: U.S. Preventive Senvices Task Force. Recommendation Statement Ann Intern Med. 2013;159:51-60. 